\title{
TACTILE CARTOGRAPHY IN LATIN AMERICA: EXPERIENCE WITH WORKSHOPS
}

\author{
${ }^{a}$ USP - University of São Paulo, walcarmo@usp.br \\ ${ }^{b}$ UNESP - São Paulo State University, carla.sena@unesp.br \\ * Corresponding author
}

Waldirene Ribeiro do Carmo ${ }^{\mathrm{a}, *}$, Carla Cristina Reinaldo Gimenes de Sena ${ }^{\mathrm{b}}$

Keywords: tactile cartography, workshops, tactile maps

\begin{abstract}
:
The process of inclusion has been occurring in schools worldwide, especially from the end of the 20th Century, thanks largely to technical advances and the development of legislation and international declarations. However, even with the championing of the principles of inclusion in education, what we see above all in most Latin American countries, are teachers who, when faced with students with disabilities and, in the case of this text, those with visual impairments, need to resort to "improvised" didactic resources; that is, they often develop material without knowing the basic principles of producing material that meets these students' requirements.
\end{abstract}

One of the main objectives of the ICA Commission on Maps and Graphics for Blind and Partially Sighted People is to facilitate this transfer of new cartographic knowledge among and within nations, above all in developing countries, by providing specialists to give workshops and courses, upon request. Accordingly, this Commission has offered several courses in partnership with researchers at the Center for Tactile Cartography of Latin America. The team of faculty members is multidisciplinary, made up of cartographers, geographers, special education teachers and designers.

In 2019, workshops were held in the Dominican Republic and in Ecuador in order to train 50 cartography professionals, as well as special education and Geography teachers. The Commission's plans included at least another two international workshops in 2020, in Argentina and Mexico.

The primary objective of the courses is to demonstrate techniques for the construction of tactile graphic representations within an inclusive educational policy, as well as to raise awareness among participants with regard to the importance of these representations in the teaching and learning of Geography and in other areas, in an interdisciplinary perspective.

The experience in offering courses permitted the development of a basic structure of the themes that are covered to meet the participants' expectations; these themes are organized into modules: cartographic concepts, map and relief illustration development and reproduction, application of maps and tactic didactic material in teaching.

However, due to the novel Coronavirus pandemic, and as a means of preventing the spread of COVID-19, all on-site activities have been suspended at schools, universities and other training centers since March 2020. Accordingly, professionals in the education area have had to adapt to a new lifestyle, due to the necessity for social distancing, and new methods of teaching (and learning), in a technology-mediated education model. Because of these exceptional times, several alternatives have been adopted in order to ensure the continuity of activities.

International workshops were postponed and those held in Brazil, which were previously exclusively on-site, had to be adapted to and held as Webinars. The duration of these on-site courses and workshops is generally four to 30 hours; however, in the online mode, this time needed to be reduced to a maximum of two hours and, accordingly, the entire approach had to be adapted.

From April 2020 to May 2021, 20 Webinars were held in Portuguese and one in English, impacting more than 1,500 people, from graduate students in Geography to primary school teachers and professionals specialized in attending to people with disabilities. Emphasis has been given to basic concepts related to inclusion and the possibilities of the use of tactile maps, both at school and for orientation and mobility, because we consider that the use of tactile geographic resources enables information barriers to be overcome, thus contributing to the integration of people with disabilities at school and work, and in everyday life, in addition to becoming a didactic resource that can be used in all classrooms and with all students.

More than teaching techniques for the construction of tactile maps or the principles of Inclusive Cartography, the purpose of these remote activities was to bring the matter up for discussion by primary education teachers and to raise awareness among students in general with regard to the theme of inclusion the appreciation of Cartography in this process. 